\title{
Why Dutch officials take bribes: a toxic mix of factors
}

\author{
Madelijne Gorsira $^{1}$ (D) $\cdot$ Wim Huisman ${ }^{1} \cdot$ Adriaan Denkers $^{2} \cdot$ Linda Steg $^{3}$
}

Accepted: 21 September 2020 / Published online: 13 October 2020

(C) The Author(s) 2020

\begin{abstract}
The aim of this study was to gain an in-depth understanding of the factors that underlie public officials' engagement in corruption. Given the significant public interest, we gained permission from the Dutch Ministry of Justice to analyze multiple confidential criminal files of cases in which Dutch public officials took bribes from private companies. Extending previous research, we analyzed three types of factors, individual factors, organizational factors, and factors related to the relationships between corrupt officials and their bribers. Moreover, for the first time, we considered the interplay between these three types of factors. The results suggest that public officials' engagement in bribery is rooted in a combination of individual, organizational and relationship variables that influence and reinforce each other, creating a toxic mix. This implies that the battle against bribery can be fought on multiple fronts, whereby changing one critical factor may cause the mix to lose its toxicity.
\end{abstract}

\section{Introduction}

A public official who takes bribes from private companies in exchange for awarding favorable contracts puts government decisions 'up for sale'. This endangers fair competition, fair prices, and trust in the government as a whole [1, 2]. To effectively counter corruption in the public sector, insight into the factors that explain it is vital. The present study aims to gain a better understanding of factors related to actual corruption that occurred in the Netherlands in the past decade.

The aim of this study is to better understand why Dutch public officials engage in corruption. Many academic disciplines have proposed explanations for corruption. However, the vast majority of empirical research has focused on finding explanations for

Madelijne Gorsira

m.gorsira@vu.nl

1 Department of Criminal Law and Criminology, VU University Amsterdam, De Boelelaan 1105, Amsterdam $1081 \mathrm{HV}$, the Netherlands

2 Erasmus School of Law, Section Criminology, Erasmus University Rotterdam, Campus Woudestein, Burgemeester Oudlaan 50, Rotterdam 3062 PA, the Netherlands

3 Faculty of Behavioural and Social Sciences, Department of Social Psychology, University of Groningen, Grote Kruisstraat 2/1, 9712 TS Groningen, Netherlands 
corruption on the national level $[3,4]$. While such studies may provide insight into why corruption is widespread in some countries and less prevalent in others, they do not explain variations within countries. In particular, these studies do not provide insight into why corruption is more likely to occur in some organizations than in others, why within organizations some people engage in corruption while their colleagues do not, nor why certain employees engage in a corrupt collaboration with a particular other. Thus, besides country-level factors, also organizational factors, individual factors and relationship factors may influence why corruption occurs. Yet, compared to country-level factors, individual, organizational and relationship factors have been far less researched in the case of corruption [5,6]. The goal of this study is to address this gap in the literature, by providing an answer to the following research question: which individual, organizational and relationship factors may explain why public officials engage in real-life corruption, and how do these factors separately play a role in corruption, as well as in combination?

The definition of corruption most widely used in scientific literature, the abuse of public power for private benefit [7, 8], includes different types of unethical and criminal behavior, ranging from conflicts of interest to bribery. This study focuses on the latter form of corruption, more specifically on the bribery of public officials by legitimate companies. This particular form of bribery is criminalized in both national and international legislation [9, 10], and many public and private organizations explicitly prohibit offering or accepting bribes in their code of ethics [11]. Bribery, therefore, violates both organizational rules (code of ethics) and the law.

While many forms of corruption can be committed either alone or with someone else, bribery 'takes two to tango'. In particular, bribery requires the involvement of both a bribe-giver and a bribe-taker. From a legal perspective, the bribe-giver engages in active bribery, and the bribe-taker in passive bribery [12]. Typically, the giver is a representative of a company, and the taker a public official [2, 13]. Our focus is therefore on bribery by a public official who expects, requests or accepts money, goods or services in exchange for a decision in favor of a private company.

Below, we briefly review the main factors that corruption research has shown to be related to corruption in general and bribery specifically. In particular, we discuss which individual, organizational and relationship factors may, according to previous empirical research, influence this form of crime. Next, we explain how the findings of these studies were used to design the present case-study analysis.

\section{Individual factors influencing corruption}

Corruption ultimately results from decisions made by individuals. Various academic disciplines have proposed different individual motives for corruption, predominantly economics, criminology, and social psychology [14]. According to economic theories such as the rational choice theory, individuals base their decisions on a cost-benefit analysis: they consider the gains from engaging in corruption, the likelihood of being caught, and the severity of punishment $[15,16] .{ }^{1}$ According to this view, corruption is more likely when people expect corrupt actions to be associated with high benefits and little costs [5, 18-20]. In criminological theories such as the routine activities theory,

\footnotetext{
${ }^{1}$ Later research has extended the rational-choice theory, by also including other explanatory factors, such as moral factors (e.g., 'A Rational Choice Theory of Corporate Crime'; [17]).
} 
the perception of opportunities to commit crime plays a central role [15, 21-23]. In applications of this theory to white-collar crime, these opportunities are related to both the job and the social status of offenders [24]. The basic idea of this theory is that corruption is more likely when individuals perceive opportunities to engage in this crime $[7,25,26]$. From a social-psychological viewpoint, it is not only important whether people perceive opportunities to engage in certain behavior, but also whether people perceive opportunities to refrain from it [27-29]. For instance, the theory of planned behavior $[27,30]$ proposes that if people experience difficulties refraining from corruption, they are more likely to engage in it. Furthermore, social psychological theories such as the norm activation model [31] and the focus theory of normative conduct [32] further propose that norms may affect corruption, particularly personal and social norms. Personal norms refer to feelings of moral obligation to engage in or refrain from certain behavior [33]. Social norms reflect perceptions of what other people think one should do, and what others actually do [32]. If people experience weaker personal norms to refrain from corruption, and if they believe others accept corruption and engage in corruption, they may be more likely to engage in corruption [34-36].

Empirical research has found that all these individual factors are related to corruption. Specifically, findings suggest that people are more likely to engage in corruption if they expect higher benefits and lower costs of corruption (see, for instance, [5, 18-20, 37]), if they perceive more opportunities to engage in, and fewer opportunities to refrain from, corruption (see, for instance, $[7,14,25,26]$ ), and if they report weaker personal norms and weaker social norms on corruption (see, for instance, [4, 34, 36, 38]).

A recent questionnaire study among a large sample of Dutch public officials examined these individual factors simultaneously in order to determine which of them are uniquely related to corruption when the other variables are controlled for, which reveals what key predictors of corruption are [14]. The outcomes indicate that personal norms, social norms and perceived opportunities to refrain from corruption best explain officials' propensity to corruption, while perceived opportunities to engage in corruption were less predictive of corruption. Moreover, in contrast to common assumptions, the perceived costs and benefits of corruption were least strongly related to corruption, suggesting that corruption is more a moral issue than a simple cost-benefit analysis [14].

\section{Organizational factors influencing corruption}

Both bribing and bribe taking is committed by offenders in occupational roles and thus occurs within an organizational context. This implies that not only characteristics of corrupt individuals themselves (the 'bad apples'), but also characteristics of organizations (the 'barrels') are likely to influence corruption [39]. Criminogenic organizational properties and dynamics belong to the most studied correlates of white-collar crime, including organizational strategies, structures and cultures [40]. As such, various organizational factors are expected to influence corrupt conduct [41]. One key factor is the actual opportunity to be corrupt: "If there is no opportunity, there will be no crime" ([42], p. 424). While it is the individual who perceives and seizes the opportunity [43], it is the occupational setting, including the organization, that provides it [44]. 
Therefore, we regard perceived opportunities to engage in corruption as an individual factor and actual opportunities as an organizational factor.

It has been argued that organizations can take several structural measures to remove or minimize opportunities conducive to corruption, as well as to find out whether opportunities are abused $[25,26]$, including the adoption of codes of conduct $[41,45$, 46], an adequate system of internal controls [47], segregation of duties [48], job rotation [48] and ethics training [46, 49]. These measures all aim to contribute to a strong 'ethical infrastructure' of organizations [50]. Empirical studies offer support for the potential effectiveness of such measures in furthering the ethicality of an organization's infrastructure, and thus, in weakening opportunities for corruption and bribery [50]. For instance, a questionnaire study on bribery found that organizations with a code of conduct reported fewer incidences of bribery [51]. Furthermore, an experimental study suggests that an adequate system of internal controls may reduce corruption [52, 53]. A study analyzing several bribery cases further indicates that the control procedures of organizations in which bribery occurred often were inadequate, while these organizations did not seem to have paid much attention to integrity policies [54]. This casestudy analysis also indicates that while the employees who engaged in corruption were able to decide on matters of great importance to external parties, there was no separation of duties regarding the activities they performed, and they worked wholly independent from others in the organization. Moreover, this case-study analysis found that corrupt employees held the same position for a long time [54]. The latter finding indicates that a lack of job rotation may increase the chance of bribery, which is in line with an experimental study that suggests that staff rotation reduces the risk of bribery [55].

Corruption within organizations may not only be influenced by structural anticorruption measures, but also by the culture or climate of an organization [56-60]. A key indicator of ethical culture or climate is leadership [46, 61, 62]. A questionnaire study suggests that type of leadership is related to employees' perception of whether or not their colleagues engaged in corruption [62]. ${ }^{2}$ Specifically, the following leadership behaviors were related to corruption: role modeling (e.g., the extent to which supervisors set a good example), strictness (e.g., the extent to which supervisors call employees to account if they violate principles and standards of integrity) and openness (e.g., the extent to which supervisors clarify the organization's integrity policy) [62]. Furthermore, a case-study analysis indicates that the supervisors of corrupt employees often failed to adequately supervise their personnel, and did not seem to respond adequately to warning signals [54], suggesting that lax supervision and supervisors' failure to act on warning signs may play a role in bribery.

\section{Relationship factors influencing corruption}

A corrupt transaction requires at least two people, who interact at least once. Scarcely any research has been done on which factors in the interaction between individuals

\footnotetext{
${ }^{2}$ This questionnaire study on the effects of leadership on corruption was not based on self-reports of corruption, but on people's perception of their colleagues' engagement in corruption (i.e., their perception of the social norm on corruption, in particular, the descriptive norm on corruption, reflecting whether corrupt behavior is perceived to be common in a setting).
} 
affect whether and why they engage in corrupt transactions. A case-study analysis based on ten bribery cases suggests that this form of corruption is more likely when the parties involved know each other well and interacted amicably before they engaged in corrupt exchanges [54]. Moreover, the perpetrators appear to exchange gifts multiple times, yet often without an explicitly voiced quid pro quo. The process of becoming corrupt seems to be a slippery slope; the corruption slowly seems to take on more serious forms [54]. However, it has also been suggested that "sometimes, the route to corruption leads over a steep cliff rather than a slippery slope" [63], indicating that bribery can also arise abruptly, instead of gradually.

\section{A case-study analysis of corruption}

To gain a better in-depth understanding of the factors underlying the engagement of Dutch public officials in corruption and bribery specifically, we conduct a case-study analysis. Case studies allow a profound investigation of the context and processes involved in corruption [64, 65]. A specific advantage is that case studies enable to analyze real-life situations in which corruption occurred. While oftentimes, case studies are conducted in explorative phases of research aiming to obtain a first impression of a certain phenomenon [54, 64], case studies are also highly suitable for validating and enriching findings of studies that are based on other (quantitative) methods [64]. Case studies on corruption and bribery specifically are rare; to the best of our knowledge, only one such study has been conducted before [54].

The present study aims to explore the role of three types of factors by means of a case-study analysis: individual motives of corrupt officials, characteristics of corrupt officials' organizations, and characteristics of the relationships between the officials and their bribers. We focus on these particular factors, because ultimately, corruption results from decisions made by individuals (in our case public officials), who operate within an organizational context and who engage in a relationship of some form with their briber. The present study not only considers how individual, organizational and relationship factors separately affect corruption, but also how they may do so in combination. In doing so, we build upon previous empirical studies on explanatory factors of corruption.

Earlier research on corruption has mostly relied on questionnaire studies and experiments to gain more insight into why individuals engage in corruption. Each of these methods has certain advantages and disadvantages [64]. More specifically, while questionnaires can provide insight into key correlates of corruption (see for instance, $[14,36]$ ) and experiments allow to identify causes of corruption (see for instance [4, 63]), an important drawback of both methods is that it is not clear whether people who report to be corruption-prone in questionnaires and who make corrupt decisions in an experimental study would commit corruption in real life as well. In addition, whereas quantitative studies have offered insight into individual and organizational factors that may affect corruption (of which the outcomes are reported above), these particular methods do not seem very suitable to study relationship factors influencing corruption, such as how relationships between public officials and their business contacts turn into corrupt collaborations in the long term. 
The present case-study analysis builds upon and extends previous quantitative studies on individual and organizational factors that may influence corruption. By studying the same individual and organizational factors by means of another method, the present case-study analysis allows to study whether important converging evidence can be found on the role these factors play in real-life corruption. In addition, it may bring these studies' findings "to life" [66]. Yet, relationship factors have not been studied before by means of quantitative research. Here, we build on the findings from the one case-study analysis on bribery that explored relationship factors [54].

Since information about the offenders' relationship with one another is essential to prove an offence of bribery, as criminal investigators and prosecutors need to find evidence of the reciprocity of gifts and services, criminal files seem a particularly important source to study the role of relationship factors, as they are likely to include such information. Therefore, our study is based on an analysis of extensive criminal files pertaining to bribery cases. The analysis of such files is particularly valuable because these files are carefully compiled by experts and contain detailed information from multiple independent sources, including interrogations of the corrupt officials and their bribers, witness interviews, taped telephone conversations and e-mail exchanges. By analyzing criminal files, this study forms an important addition to previous, mostly quantitative, research on explanations for corruption. In particular, it may deepen our understanding of individual factors that may make people open to bribery, organizational factors that may contribute to the risk of bribery, and relationship factors that may make the transition of a business relationship to a corrupt collaboration more likely, while also allowing to gain insight into the interplay between these different factors.

\section{Method}

We analyzed confidential criminal files of bribery investigations conducted by two Dutch investigation services: the National Police Internal Investigations Department, ${ }^{3}$ and the Fiscal Information and Investigation Service. ${ }^{4}$ Permission to conduct the study was obtained from the Ministry of Justice and Security under the Police Data Act (in Dutch: Wet politiegegevens). ${ }^{5}$ Access to these data is granted only if the research serves "a significant public interest". The extensive criminal files included records of the interrogations of suspects, as well as other sources such as taped telephone conversations, e-mail exchanges and witness interviews. Hence, besides perpetrators' statements, the files included statements by witnesses (e.g., supervisors and colleagues) about the corrupt officials, the organizations they worked for, and their relationships with the bribers.

The National Police Internal Investigations Department is a Special Investigation Service of the Dutch police and plays a leading role in investigating corruption in the Netherlands [67]. It investigates allegations about conduct of government officials and

\footnotetext{
${ }^{3}$ Known in Dutch as the Rijksrecherche.

${ }^{4}$ Known in Dutch as the Fiscale Inlichtingen- en Opsporingsdienst.

${ }^{5}$ Wet van 21 juli 2007, houdende regels inzake de verwerking van politiegegevens (Wet politiegegevens), Staatsblad 2007, 300.
} 
public servants ${ }^{6}$ that severely affect the integrity of or the way in which government operates. ${ }^{7}$ The Fiscal Information and Investigation Service is a special investigation service of the Tax and Customs Administration and responsible for tax investigations. ${ }^{8}$ It aims to help prevent fiscal, financial and economic fraud, to ensure the integrity of professionals and businesses, and to fight against organized crime. ${ }^{9}$ We studied corruption files at the Service's Bureau of Integrity and Security, ${ }^{10}$ which is responsible for handling and registering allegations of severe integrity violations involving Tax and Customs Administration employees.

\section{Selected cases}

The National Police Internal Investigations Department provided an overview of all cases registered in a four-year period ${ }^{11}$ between 2004 and $2014^{12}$ under the heading of 'corruption'. ${ }^{13}$ This overview contained 94 cases with a short description of the respective case. Forty-two of the case descriptions did not correspond to this study's operationalization of corruption. ${ }^{14}$ For 22 of the 52 remaining cases, no report or criminal files were produced, for instance because of a lack of information. As a result, 30 potential bribery files of the National Police Internal Investigations Department were examined. With regard to the Bureau of Integrity and Security of the Fiscal Information and Investigation Service, all possible corruption cases registered between 2004 and 2014 where the full or part of the file was available at the Bureau were examined. This resulted in 13 criminal files relating to corruption investigations. Hence, a total of 43 potential bribery cases were examined in the initial analysis. We then selected cases that met the following selection criteria:

1. In all probability, the behavior investigated concerned 'real' bribery: at least one of the persons involved was convicted of bribery, ${ }^{15}$ and/or the public official and/or the briber confessed to the offense;

\footnotetext{
${ }^{6}$ www.om.nl/algemeen/english/about-the-public/organisation-the/.

${ }^{7}$ www.transparency.org/whatwedo/publication/national_integrity_system_assessment_netherlands.

8 www.iaaca.org/AntiCorruptionAuthorities/ByCountriesandRegions/N/Netherlandsjigou/201202/ t20120210_802454.shtml.

${ }^{9}$ www.transparency.org/whatwedo/publication/national_integrity_system_assessment_netherlands.

${ }^{10}$ In Dutch, Bureau Integriteit en Veiligheid.

${ }^{11}$ We have chosen not to specify the exact time period so as to prevent the parties involved becoming traceable.

12 This timeframe was chosen because it meant that the behavior investigated was of a fairly recent date. However, the criminal investigations had generally closed by the time the data analysis started (in January 2015). In most cases, therefore, the decision on whether to prosecute and, if applicable, the sentence ultimately imposed were known.

13 The definition of corruption used by the National Police Internal Investigations Department when registering cases aligns with the rather broad definition of corruption used by Transparency International: the abuse of entrusted power for personal gain.

${ }^{14}$ Owing, for instance, to suspicions of an insurance fraud (rather than bribery).

${ }^{15}$ One of the offenses covered by Articles 362-364 (passive bribery of public officials) or 177-178 (active bribery of public officials) of the Dutch Penal Code.
} 
2. The act concerned bribery involving a public official ${ }^{16}$ and a company representative;

3. The bribery took place in the Netherlands.

Of the 43 cases investigated, 7 met the selection criteria. The most common reasons for the other 36 cases not meeting the criteria were insufficient evidence for bribery, or the involvement of a criminal organization rather than a legitimate company. With regard to one of the seven cases, a file was available at both the National Police Internal Investigations Department and the Fiscal Information and Investigation Service. Hence, the present study's analysis is based on seven bribery cases and eight bribery files.

The data analysis took place at the National Police Internal Investigations Department and the Bureau of Integrity and Security of the Fiscal Information and Investigation Service over the course of several months. The first author analyzed the selected cases on the basis of a scoring form that included the individual, organizational and relationship factors discussed in the introductory section (the scoring form is included in Appendix 1). During the process of data analyses, we decided to focus our analysis of organizational culture on leadership as a key indicator of (ethical) culture, as the criminal files contained a lot of information on the role and behavior of the corrupt officials' supervisors, while the criminal files hardly comprised information on the organizational culture itself (which we intended to assess using a model of [57], that was included in the scoring form); the criminal files did not contain relevant information to score the ethical virtues included in Kaptein's model.

For each of the seven cases, text within the respective file reflecting the role of each type of factor was noted on the scoring form. After the first author completed the data collection, the second and third author visited the National Police Internal Investigations Department and the Bureau of Integrity and Security to check whether the completed scoring forms were in line with the information included in the files, and whether any important information was missing. No major disagreements were encountered. Besides the seven bribery case files, other available sources were studied, including newspaper articles and court judgments on the particular case (as the court judgments were not part of the criminal file). ${ }^{17}$

The data analysis was conducted between January 2015 and October 2015. Given the extensive nature of the files, the recording was rather time-intensive, involving a total of around $400 \mathrm{~h}$. After having collected the data and categorizing the data on the basis of the scoring form per case, the first author conducted the overall analysis of the seven cases. Subsequently, the first author drew case-transcending conclusions per factor (for instance, for personal norms: 'None of the public officials acknowledged the moral reprehensibility of their actions'), and, together with the second author, selected quotes illustrating the main conclusions.

The results reported below detail the main findings for each factor separately, illustrated by relevant statements of the suspects and/or witnesses. In the quotations, the corrupt officials are all referred to as ' $\mathrm{X}$ ', while the company representatives who

\footnotetext{
$\overline{{ }^{16}}$ This includes civil servants from municipal, provincial, water and national authorities, as well as officials of certain other organizations appointed by the state to perform public tasks.

${ }^{17}$ Following the outcomes of the criminal investigation, two of the officials were forced to take early retirement. The other five officials were subjected to criminal prosecution. Two officials were given a community service and suspended prison sentence. The other three were given a custodial sentence.
} 
bribed them are referred to as ' $\mathrm{Y}$ '. Before reporting the results, we briefly describe the seven cases, specifically characteristics of the individuals involved and the corrupt gifts exchanged. This is followed by information on the perpetrators and their offenses.

\section{Case descriptions}

Case 1. An official went on a golf trip abroad with some business contacts, with whom he had also had golf lessons. Whereas the official stated he had paid for the golf lessons and the trip abroad himself, the criminal investigation showed that these had been paid for by the director of a painting and maintenance company and the director of a paint manufacturer, who hoped to be awarded public contracts in return.

Case 2: An official accepted envelopes containing cash from the owner of a sand and gravel company, who was awarded public contracts in return.

Case 3. Over a period of several years, an official accepted money, goods and services from a business contact who worked in the import business. In exchange for this, the official did not check the falsified tax forms that the importer submitted on an almost daily basis.

Case 4. An official accepted two envelopes containing cash and the promise of a holiday from two of his business contacts who owned a bar. In return, the official influenced legal proceedings in favor of the bar owners, or at least gave them this impression.

Case 5. An official with high debts as a result of being addicted to alcohol and drugs provided hundreds of confidential documents to an owner of several companies, who used this information to commit fraud. In return, the latter helped the official to manage and reduce his debts.

Case 6. A prominent official awarded multiple public contracts to two of his business contacts, both of whom owned a company. In exchange, the official received hundreds of thousands of euros via his own private company.

Case 7. A prominent official used his influence to create favorable conditions for several construction and real estate companies so that, for example, prestigious projects could continue. In exchange, the official received hundreds of thousands of euros via his own private company.

\section{Background characteristics of the offenders and their office}

In each case, one public official was suspected of bribery. Yet, in four of the cases, the official in the respective case accepted, expected or requested bribes from multiple company representatives, with the total number of bribers amounting to eighteen. With regard, therefore, to the relationship factors, this case study analysis is based on 18 corrupt collaborations. All 25 perpetrators 
(seven officials and eighteen company representatives) were male. At the time of the offense, all 25 offenders were between 40 and 65 years of age. Except in case 5, all public officials were responsible for deciding on issues of importance to the private sector, and interacted professionally with the private sector on a nearly daily basis. These contacts mainly comprised the awarding of contracts, enforcement and inspection, handling of and access to confidential information, and spatial planning. Five of the seven officials had been working at the same government agency for almost or more than forty years.

The files suggest that all seven public officials were known to be very experienced, skilled, and result-oriented. A colleague of one of the officials stated that " $X$ was very experienced, someone who could get things done." The officials did not appear to view themselves as 'typical public officials'; as one said, "I didn't feel like a civil servant." Nor were they seen as such by others. As a colleague remarked, "I had the impression he was more of a businessman than a civil servant." Except for the official in case 5, all the officials were characterized by others as 'fixers', as hard-working and skillful negotiators able to get things done. A business contact described the official as "A tough negotiator. I had never encountered anyone like him before at a municipality", while another official's colleague stated that "They all knew him. He obtained many grants and was very slick at that." The officials were known to have extensive networks, particularly in the private sector, and to enjoy being with their business contacts, which was also noted by their colleagues: "I lived in a different world than $X$ did. I didn't have that many contacts with real-estate people."

\section{Results}

\section{Individual-level factors}

\section{Perceived benefits of bribery}

All seven officials benefited financially from their crime. In some cases, the financial gain was substantial (i.e., hundreds of thousands of euros), while in other cases the gain was relatively small (i.e., a few hundred euros). Interestingly, the financial benefit to the company representative(s) was in most cases much higher than the financial benefit to the official. In all cases, intangible benefits, particularly the desire to be part of and respected by the private sector, ${ }^{18}$ seem also to have played a role. Other non-financial gains that may have prompted the officials to engage in bribery include pleasure and status. One briber for instance stated about the official that "He liked to feel important." In some cases, frustration may also have played a role. One company representative said about an official that the official "... was frustrated and felt obstructed. For example, he wanted to invite companies to submit bids, but was overruled by a superior. He said he was done with it, and wanted to make some kind of arrangement so that he could retire early."

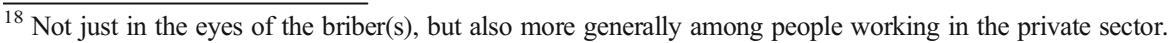




\section{Perceived costs of bribery}

The files suggest that at least four of the officials considered the possibility of being detected. These officials tried to conceal their corrupt practices, with some of them committing forgery for this purpose, while others tried to hide evidence, for instance by stapling a tax form in such a way that it concealed incriminating information: "The chance is low, but if the tax form is picked out of the archive to be checked by a colleague, I can just say I didn't see it [i.e., the incriminating information] because of the staple [i.e., which hid the incriminating information; a forged number]. Y knows this as well and keeps it in mind." Alternatively, the corrupt officials sought to create the impression that other people, in addition to themselves, had been involved in performing a certain task by, for instance, using a colleague's user ID as "I wanted to create the impression that more colleagues had been involved in dealing with the tax declaration." Two of the officials seem to have intimidated colleagues to prevent these colleagues from obstructing them. One of these officials said to a lower-ranked colleague who wanted to blow the whistle, "If you are accusing me of breaching integrity, then you'll find out what happens; it won't be easy for you." Another official chose a subtler approach. He gave small gifs to some of his colleagues, who were not always aware these gifts actually came from the company representative. The corrupt official told the criminal investigators that if these colleagues had wanted to blow the whistle on him, he could have told them they were guilty of the same behavior they were accusing him of, as he could say to them: "You yourself have also received something for nothing from Y." Two of his colleagues, however, knew the gifts they got came from the company representative. The official told the investigators that the gifts to these colleagues "..were meant as a kind of hush money." Hence, the officials seemed to have tried to hide their corrupt practices by camouflaging evidence or by intimidating or 'greasing' colleagues.

The costs of engaging in bribery include not only the perceived chance of detection (and efforts undertaken to reduce this risk), but also the perceived severity of the consequences of engaging in corrupt practices. One official's statement implied that he had not been fully aware, or at least had not taken account, of the consequences for himself of engaging in bribery ${ }^{19}$ : "This is a depressing situation. I think this will cost me my job. I could have used the old early retirement scheme, but now I'll have to work until I'm 65. I momentarily lost control over my life and cannot fully foresee what will happen."

\section{Perceived opportunities to engage in and refrain from bribery ${ }^{20}$}

In most cases, the officials seem to have been all too eager to utilize, and increase, the opportunities for bribery. As one of them said, "Wherever I could, I steered decisionmaking powers in my direction." Colleagues also noted that the corrupt officials maneuvered themselves into situations enabling independent decision-making on important matters regarding their business contacts. For instance, a colleague said " $X$ has

\footnotetext{
${ }^{19}$ Or his statement indicates that he miscalculated the chances of his offense being discovered.

${ }^{20}$ Perceptions of opportunities for bribery depend, of course, on actual opportunities. This factor is discussed later (see structural organizational factors).
} 
got his regular clients for whom he handles almost all their tax forms. No other colleagues get involved." Especially the officials in higher-level positions appear to have personally created opportunities for bribery by, for instance, appointing inexperienced team managers. As one such manager put it, "Because I was a junior manager, I always accepted X's guidance and advice. Solicited and unsolicited, he gave me instructions. After deciding to hire temporary workers, we selected an agency. $X$ always proposed and approached the agency. Generally we hired employees through $<$ name of Y's company>. The higher management wasn't to be involved." Another team manager said the following about the corrupt official's role in awarding public contracts: "A very big role. He decided. We didn't have a say in it. He took the decisions, that's it." Hence, the opportunity not only made the thief, but corrupt officials appear also to have created opportunities for themselves.

In one case, the records suggest that a lack of opportunity to refrain from bribery may have played a role. Over many years, the official had repeatedly reported to his supervisors that he was concerned that it was impossible to check tax forms (including forms the company representative forged) properly. Yet no action was taken. The official's supervisor acknowledged this problem to the criminal investigators: "There are work instructions for the employees, but, in all honesty, there is insufficient staff to follow the guidelines by the book."

\section{Personal norms on bribery}

None of the public officials acknowledged the moral reprehensibility of their actions whether in the taped telephone conversations prior to their arrest, during interrogations or in court - irrespective of whether they confessed to the bribery. ${ }^{21}$ As one of them stated, "I did not do anything wrong. If I faced the same situation, I would make the same decisions again." In particular, none of the officials seemed to feel responsible for the bribery itself, nor did they acknowledge the negative consequences of their corrupt practices. As one of them said: "I did not jeopardize the integrity of the [name of X's public service].", despite accepting a free golf trip abroad from a business contact who anticipated to be awarded favorable public contracts in return. The officials' statements suggest that they did not feel they had violated their personal norms on bribery possibly because the personal norms of the corrupt officials were weak from the start and failed to function as a 'moral break'. As one official said, "I was fine with receiving the sums of money from $Y$ ", while another official said "I accepted it and said 'thank you'. I didn't have to do anything, just look the other way." A lack of feelings of moral obligation to refrain from bribery may explain why the officials engaged in it (while other people do not) and might explain as well why all the officials appeared devoid of regret and remorse. This was also noticed by the court, as the following three court judgments illustrate:

- "The court has noticed during the trial that the defendant has shown no awareness of the immorality of his actions. The impression is that the defendant considers himself more a victim of this case than a culprit."

\footnotetext{
${ }^{21}$ Only one of the 25 perpetrators, who was not an official but a company representative, stated in court that he felt bad about what he had done.
} 
- ".... this justifies the conclusion that the defendant does not recognize the severity and moral reprehensibility of his actions."

- "The suspect has also demonstrated during the trial that he is unable to recognize the immorality of his actions."

\section{Social norms on bribery}

Five of the seven officials stated that some of their close colleagues engaged in or accepted similar conduct. One official indicated that his colleagues had received gifts from business contacts, like he himself had: "That he received it was sort of part of the culture, the normal way of getting along. And also these little things [i.e., the gifts] were part of that atmosphere. You know each other for such a long time, then these things happen."

However, the officials' statements regarding the socials norms on corruption did not always seem to correspond to reality. One official said, "We all did that. Several colleagues of mine also played golf with their business network." Criminal investigator: "How many colleagues?". The official: "I estimate half of my colleagues." However, a witness from the private sector stated about playing golf with the official: "That was only with X." Investigator: "Were there any other public officials at the golf course?". Witness: "No, not that I'm aware of. There was always only one official. That was X."

Nonetheless, colleagues of four other officials do seem to have accepted gifts from business contacts as well. In these instances, however, the role played by the corrupt officials themselves should not be overlooked. One official, for instance, provided a colleague with tips on how to 'safely' accept money (i.e., bribes) from his business contact: he advised his colleague to receive the payments through his own private company, but to appoint someone else as the company's director (just as the official himself had done). In another case, the official, together with his briber, seemed to have deliberately tried to involve colleagues of the official who seemed susceptible to bribery. The company representative said about the gifts he gave to some of the official's colleagues: "That's not about money or whatever, but small things. I never had a connection with the other people [i.e., other colleagues of X]. That was not deliberate, so not that I deliberately left other people out of it." Note that the company representative's statement that he did not "deliberately [leave] other people out of it" may also suggest that he did intentionally 'leave some people in on it'. By offering gifts to the official's colleagues, the company representative may have reinforced the corrupt official's perception that corruption was approved of and common among his colleagues, thereby shifting the social norms on bribery within the official's department.

\section{Organizational-level factors}

\section{Structural organizational factors}

All government organizations in the Netherlands are required by law to pursue an integrity policy aimed at promoting proper conduct by civil servants. For instance, organizations have to adopt a code of conduct and have to discuss integrity-related 
issues in performance appraisal interviews. Moreover, according to the Civil Servants Act (in Dutch: Ambtenarenwet) all civil servants have to swear an oath or make an affirmation when they are appointed). ${ }^{22}$

Although the organizations of the corrupt officials all seem to have complied with the legal obligations, such as adoption of a code of conduct, they did not seem to have taken all relevant measures that may effectively prevent or stop bribery. In particular, in all cases, one or more of the following structural anti-bribery measures were lacking or inadequately implemented, which provided the corrupt officials with (more) opportunities to engage in bribery and to continue doing so: segregation of duties, internal controls, job rotation and a reliable reporting system. For instance, in one of the cases, a corrupt official's direct supervisor stated in a witness interview that he found it strange that higher management apparently did not realize the risks they were exposed to, specifically that: “... one man [i.e., X] is responsible for identifying, solving and paying for a problem [i.e., maintenance works].”, indicating that with regard to the activities the corrupt official performed, there was no segregation of duties. A colleague of another official told the criminal investigators that while a formal system of separation of duties was in place, it was not adequately implemented in practice: "There is a fairly strict segregation of duties between the front office [i.e., where tax forms are submitted] and the back office [i.e., where the forms are handled], but there is no segregation of duties at a personal level. That is not even possible as all the employees who work at the front office also work in the back office." This, of course, completely nullifies the rationale for segregation of duties. Besides separation of duties, internal controls were often inadequately implemented, or even absent. As a town clerk who had worked with one of the corrupt officials said, "The only one who monitors the activities is X. No one monitors X's activities." Besides the absence of segregation of duties and adequate controls, the criminal files indicate that some of the officials had held the same position for a very long time, implying a lack of job rotation. Hence, the officials' organizations did not seem to have implemented all the relevant structural measures that could have prevented or stopped bribery, despite most of the officials being in a sensitive or sometimes very sensitive position with regard to bribery.

\section{Leadership}

In six of the seven cases, there had been warning signals about the officials' behavior in terms of integrity, and in five of these cases these signals had been known to their organizations. However, the supervisors of these six officials did not seem to have responded to these warnings. As one supervisor stated when the criminal investigators asked him why he did not act upon the signal of corruption that reached him, "I did not judge it as relevant." When the investigators asked "Why did you not discuss these signals with X?", the supervisor said "That thought did not even occur to me." 23 When told by the investigators that his subordinate had a prior conviction for bribery, another official's supervisor said, "I think he should have immediately [i.e., when the supervisor hired the official] been frank with me about what had happened at the previous

\footnotetext{
22 Article 7 Ambtenarenwet 2017, Staatsblad 2017, 123.

${ }^{23}$ It is not possible to determine whether this statement is really true. The fact remains, however, that the official's supervisor did not take any action in response to the warning signals reaching him.
} 
municipality. If he had been frank at that moment, I believe I would have tried to hire him anyway. Of course, I don't know if I'd have succeeded. Our relationship also offered plenty of opportunities for him to tell me." This statement suggests that this supervisor did not reject the possibility of hiring corruption-sensitive employees.

Not only the direct supervisors, but also senior management seemed not to have responded adequately to warning signals reaching them. After it became known that $X$ had engaged in an integrity violation, senior management sent an e-mail to the relevant department stating that "Without any reservation, there is no doubt whatsoever about $X$ 's integrity. Therefore, there is no objection at all to fully employ $X$ again in the $<$ name of the work process $>$." The criminal investigation revealed that the official in question was already engaged in bribery at the time this e-mail was sent.

Hence, integrity did not seem to have been a major issue, or at least not a priority, for the officials' supervisors. The corrupt officials' high performance may have been a significant explanation for their supervisors' seemingly lax attitude towards integrity violations. Three of the officials were awarded or recommended for a bonus for exceptional performance, despite their supervisors knowing that two of them had committed integrity violations (while the third official who was awarded a bonus had been suspected of bribery in a previous criminal investigation).

In all but one case, the officials' superiors do not seem to have supervised the officials and their activities properly. Despite an official previously having been reprimanded for an integrity violation, his supervisor stated that "I assumed, as long as there were no signals, that he [i.e., X] was sticking to the agreements. There were no signals." A former supervisor of one of the officials responded as follows to a question about whether he had ever discussed the procurement policy with the official: "Not really, he was given a lot of freedom. As long as he stayed within the budget, he could do what he thought was best. I supervised from a distance. $X$ did not need special guidance. There was no real supervision. It was more a case of discussing issues with each other." The criminal investigation later found the official to have violated the procurement policy.

Two cases contained indications that the officials' supervisors had not set a good example: they themselves seem to have breached integrity rules. The supervisor of one of the officials had performed ancillary activities for a business contact that interfered with his office. The business contact for whom he performed these activities for was the exact company representative who later bribed the official (i.e., the supervisor's subordinate). The official in this case also knew about the outside activities his supervisor performed for the company representative. In addition, some people in higher management seem to have held loose beliefs about integrity. In particular, one of the officials worked intensively with a municipal alderman whose statement implied that, despite having integrity in his remit, he had a rather shallow interpretation of the concept: "Before 2006, integrity had no official position in the organization. By introducing it, we have shown that integrity is important." This alderman, who knew about a previous integrity violation by the official and was aware of new signs suggesting that something might be amiss, shared his interpretation of the concept of integrity in a witness interview: "Integrity policy mainly has to do with perception management and protecting your own people." 


\section{Relationship-level factors}

\section{Relationship between officials and company representatives}

The relationships between the officials and the company representatives were generally enduring relationships, ranging from a few months to, in three cases, more than fifteen years. Almost all eighteen relationships originated in the business sphere. Indeed, 'business interests' seem in all cases to have been the driving force behind the relationships. However, over the course of time these relationships seem to have become more intensive and more amicable. Taped telephone conversations and email exchanges show, for example, some of the officials and the company representatives using words such as "friend" and " $b u d d y$ " to address one another - although none of the relationships can be qualified as 'real' friendships. The contacts between the offenders were also remarkably intensive. As one official said about his visits to the representative's company, "Sometimes I didn't visit for a few consecutive days", which implies that he was a regular 'guest' almost every other day. The company representative, in turn, frequently visited the government service where the official worked. As he stated, "I was one of the regulars."

The meetings between the officials and company representatives took place not only at work and during working hours, but also outside work and working hours in, for example, restaurants and cafes in the evening and on Saturdays. An official said that "On Saturday I visit my mother and then pass by Y." This official was nonetheless of the opinion that "I strictly separated private and business matters." Perhaps the frequent, intensive and relatively personal contacts between the officials and the bribers blurred the boundaries between their work and private lives, thus paving the way for the onset of the corrupt collaborations.

\section{Corrupt collaborations}

In the case of fifteen of the eighteen relationships, the contacts did not seem to have developed into corrupt collaborations immediately. But when they eventually did, they were rarely limited to a one-off exchange. As mentioned before, some cases contained indications that the bribery started with small gifts or services. According to a company representative, "Sometimes it really was about trifles." The gifts that were exchanged did not always stem illogically from the situation, at least not in the officials' view. The official who visited the company representative outside working hours to collect tax forms stated with regard to the free fuel he got from the company representative that "He filled my car up with fuel as a friendly gesture. I received this for dropping in. For me it was a matter of trivial company spillage."

In many cases, it was not entirely clear who took the initiative and who came up with the bribery construction. At first glance, it often appeared to have been the company representative who took the initiative. One said: "I want to emphasize that $X$ himself never asked me for money or whatever. I told him it was a little bit of holiday money." In many instances, however, the officials appear to have sent certain signals that may have triggered the corrupt offer. When the company representative handed over an envelope containing money, the official said (the meeting was recorded by the police) "You don't look a gift horse in the mouth. I'm not like that. I never make any 
demands...", which suggests this was not the first (and neither the second) time he had taken bribes from a business contact.

The compensation expected in return was often not explicitly voiced. As one official said, "I later sensed what compensation I had to provide in return." The statement by a company representative in another case also indicated that the corrupt exchange was not 'put into words': "X did not tell me, for example, that he wanted to get that amount. He spoke as if he was telling you that you had to give him something, that he wanted something from you." This was very similar to the experience of another company representative, who said about the official that "When he told me that, he looked at me as if to say 'Now I'll probably get something for that'. Because of what he said and how he looked at me, I decided to tell him he would indeed get something for that." As the bribery generally took place in enduring relationships, and the gifts seem to have gradually increased in both size and frequency, it was difficult in some instances to pinpoint the initiator and the exact starting point of the corrupt collaboration - perhaps also for the perpetrators themselves.

In some cases, there are indications that the bribery developed gradually, and increased in severity over time. According to a company representative, "... but I didn't charge anything for that [i.e., for the small gifts to $\mathrm{X}$ ] ... and that's how it gradually grew." Indeed, some officials' statements suggest they 'slipped' into bribery: "It slowly developed into me accepting money from $Y$, and then there's no way out. You're often deeper in it than you realize. The last few years, when he started with the new $<$ name of merchandize>, that's when I thought ' $s * * t$ ', then I really realized what I had got the money for, but then there was no turning back." Another official seemed to have had a similar experience; as he put it, "At one point I thought that $Y$ was actually asking too much from me. But I was too deep in it already. There was no way back." In these cases, the process of corruption can be seen as a slippery slope, a subtle and lengthy process in which the perpetrators gradually engaged in bribery on an increasing scale.

\section{Toxic mix of individual, organizational and relationship factors}

Separately, the above individual, organizational and relationship factors may not have resulted in bribery. However, in the cases we analyzed, they often seem to have cooccurred and, in combination, to have formed a toxic mix. Indeed, the factors seemed not just to converge, but also to reinforce each other, thereby increasing the mix's toxicity. The officials' interaction with the bribers may, for instance, have weakened the officials' personal norms on bribery, and may specifically have confirmed the officials in their view that their actions were not so bad and certainly not criminal. For instance, after police had searched the home of one of the officials for evidence of bribery, the company representative who bribed him called him and said (this conversation was recorded on tape): 'It's unbelievable. It doesn't seem to stop. It's as if you're a goddamn criminal. And you don't have a yacht of one and a half million. You ... you... you just live a decent and proper life and you like nice food, that's all." The convergence of and interplay between factors at multiple levels was also illustrated by an e-mail sent by a colleague of one of the officials to the criminal investigators. In this e-mail, the colleague wrote that, in his view, his superiors' failure to intervene after a previous integrity violation by the official deserved to be qualified as "criminally naïve." He added sarcastically, "In that context [i.e., X's earlier integrity violation] it 
obviously makes sense not to carry out internal controls in four consecutive years, not to organize regular staff meetings, and not to make public the complaints from staff, citizens and companies about the wrongdoings and fraud: you could work 'pleasantly' in a culture of indifference. After all, 'What the eye doesn't see ... isn't going to hurt you'. And the result of that: a colleague [i.e., X] getting fired and going to be prosecuted, and colleagues who are, by nature, well-intentioned get sucked into it.

\section{Discussion}

The aim of this case-study analysis was to gain a better in-depth understanding of the factors underlying the engagement of Dutch public officials in corruption and bribery specifically. Extending previous research, we analyzed unique information from extensive confidential criminal files of bribery cases to explore the role of three types of factors (including individual motives of corrupt officials, characteristics of corrupt officials' organizations, and characteristics of the relationships between the officials and their bribers), while also for the first time considering the interplay between these different factors. In doing so, we additionally examined whether individual and organizational factors that have been revealed as predictors of corruption and bribery in questionnaires and experiments play a role in real cases as well.

With regard to individual factors, the criminal files imply that the corrupt officials expected bribery to result in both material and non-material benefits; deliberately tried to reduce the chances of detection; perceived opportunities to engage in one or more acts of bribery, and, to a lesser extent, experienced it as difficult to refrain from bribery; did not recognize the severity and moral reprehensibility of their actions; and believed that their close colleagues accepted or engaged in similar corrupt conduct. Regarding organizational factors, the findings suggest that the organizations the corrupt officials worked for failed to take certain relevant anti-bribery measures, such as separating duties and ensuring job rotation, despite the corruption-sensitive nature of the activities the officials who later became corrupt performed. In addition, the criminal files suggest that the supervisors of the corrupt officials did not properly monitor the corrupt officials and their activities, did not set the right example, and did not respond adequately to the warning signals that were present in almost all cases. With regard to relationship factors, the results suggest that the officials and the company representatives who bribed them had an enduring, personal and intensive relationship. The officials met the company representatives not only at work, but outside work and working hours, which may have blurred the boundaries between their work and private lives. In most cases, it was unclear when the bribery precisely started and who instigated it. One of the reasons for this was that the corrupt collaboration sometimes started with small gifts that gradually increased in size, while the reciprocal obligation was often not immediate nor always explicitly voiced.

Our case-study analysis supports findings from questionnaire studies and experiments regarding different individual and organizational predictors of corruption, providing important convergent evidence of the possible influence of these factors on reallife corruption. In particular, our results suggest that the factors found to be related to corruption in questionnaire and experimental studies play a role in actual corruption as well. Extending previous quantitative studies, our findings additionally reveal that 
relationship factors seem to play a key role in the development of the corrupt collaboration between officials and company representatives, not only in its onset, but also in its aggravation.

Importantly, extending previous studies, our study considered all three types of factors in combination, and found that individual, organizational and relationship factors all play a role in the onset and/or continuance of corrupt collaborations, and seem to become particularly harmful as they co-occur. An important conclusion of this study therefore is that corruption seems to be the result of a combination of factors, and not of one of a limited number of 'prominent factors'. When these various types of factors converge, they seem to form a toxic mix. In fact, the factors do not just converge, but also seem to influence and reinforce each other, thereby increasing the mix's toxicity. Indeed, the different cases suggest that the corrupt officials all worked hard and were able to get things done. As a result of this, they were highly valued by their supervisors, who may therefore have turned a blind eye to signals of integrity violations. The officials' ability to get things done - things their colleagues were unable or unwilling to do - was also noticed by their business contacts, as was the officials' desire to be part of and respected by their business relationships. The officials saw the company representatives on a regular basis, not only at work, but also outside work and after working hours. At such moments the officials were offered small gifts, as a thank you from the company representatives, for the extra efforts they had made. These gifts gradually increased in size and frequency, while the officials' personal norms seemed to be weak or weakened and did not function as a 'moral brake'. The public officials, in turn, had the opportunity to return the favors since they typically enjoyed full discretionary powers on issues of importance to the company representatives. These practices were not detected, even when they increased in frequency and severity, owing to a lack of job rotation or segregation of duties, or a lack of properly implemented controls, or even no controls at all being in place. The officials further reduced their chances of being detected by 'greasing' their colleagues, thereby shifting the social norms on bribery. Consequently, the officials' corrupt behavior not only persisted and worsened over time, but also spread.

This case-study analysis has a number of strengths and weaknesses. A potential weakness is the limited number of cases on which the results are based, with only seven cases meeting our selection criteria, including eighteen corrupt collaborations. Yet, importantly, our results are substantiated by evidence from multiple sources, including dozens of witness interviews in each case. Moreover, our analysis reveals that similar factors appeared to play a role in all corruption cases, which, importantly, also seem to be in line with results from previous studies on explanatory factors of corruption, suggesting that factors previously identified as predictors also played a role in real-life corruption.

A clear advantage of analyzing criminal files is that little doubt exists that the dependent variable is actual corruption, while this can be a concern in quantitative studies such as research based on self-reports. A limitation of studying actual cases is, however, that it is unclear whether the corruption being studied is representative of all corruption occurring. In particular, our case-study analysis necessarily included only cases that have been detected and subject to criminal investigations. It is not inconceivable that bribery cases that are being criminally investigated differ from cases that have not been detected and investigated. Notably, certain 'types' of corrupt 
collaborations committed by certain 'types' of offenders may be more likely to come to light and to be criminally investigated than others, in particular, offenders who engage openly in intensive relationships with their bribers, and who engage in multiple corrupt exchanges, like in the present study. Since acts of bribery committed by officials who maintain less ostentatious contacts with their bribers and who engage in a single corrupt transaction may be less likely to be detected and criminally investigated, the analysis of actual corruption cases may result in a biased, or at least partial, view of corruption and the factors that affect it.

Another possible limitation of this study is that our analysis was based partly on statements by suspects in an interrogation situation. The 25 suspects may have intentionally lied to protect themselves or others. Yet, many of our findings are in line with other studies on corruption that employed different methods that do not rely on the truthfulness of suspects in an interrogation situation, such as experiments. Additionally, our analysis was not just based on the statements of the subjects themselves, but also on information gathered by the police before the perpetrators knew they were a suspect, such as taped telephone conversations and e-mail exchanges, and on information provided by people other than the suspects.

The outcomes of this study suggest that various types of factors converge to form a toxic mix. This convergence is reminiscent of Routine Activities Theory, which explains crime as the outcome of the convergence of motived offenders, suitable targets and absence of guardianship in time and place [22]. The present study illustrates the role of personal and social norms in motivating public officials into bribe-taking. Corruptors and corruptees meet in criminogenic contexts. Opportunities typical for white-collar crime typify the case-studies of corruption, as access to these situations comes with public office, while the corrupt exchanges have the superficial appearance of legitimacy [68]. And equally typical for white-collar crime, guardianship was lacking due to failing managerial oversight and absence of organizational restraints, providing ample opportunity for corrupt exchanges. This study however also shows that corruption is not just a convergence in time and place, but a dynamic and continuous process involving long lasting personal relationships.

Despite the inclusion in our study of different types of factors stemming from different academic disciplines, our analysis may not include all the factors that strengthen the mix's toxicity. An example of such a factor is the use of neutralization techniques, which may affect individual motives for corruption, in particular, feelings of moral obligation to refrain from corruption (i.e., personal norms). Neutralization techniques are mental strategies that allow offenders to view their engagement in an act of crime as justified. While initially identified to understand juvenile delinquency [69], neutralization techniques have been found particularly relevant for understanding white-collar crime [70, 71] and corruption in particular [41, 45, 54, 72]. Techniques of neutralization are likely to be used if a person considers corruption to be (somewhat) wrong, and so feels the need to justify his or her engagement in it. Corrupt behavior that is at odds with someone's initial moral standards gives rise to an unpleasant tension (see also [73]). This cognitive dissonance can be removed or reduced either by not engaging in the behavior anymore, or by neutralizing, and thus weakening, one's moral conviction to refrain from it $[74,75]$. Hence, a self-reinforcing process may occur: relatively weak personal norms precede an individual's engagement in corruption and may partly explain why some people engage in corruption while others do not, while 
personal norms may also be further weakened through the use of neutralization techniques [76]. Importantly, such a dynamic interplay between weak personal norms, the engagement in corruption, and the use of neutralization techniques to further weaken personal norms, may pave the way for future acts of corruption, as people may feel less and less morally obliged to refrain from corrupt deeds over time, even ones of a more severe nature. This process may continue until the need to justify one's engagement in corruption fades completely; when people are liberated "from the shackles of their morality altogether" ([77], p. 37). Further research is needed to examine whether and how neutralization techniques contribute to people's engagement in corruption, and in particular whether these techniques erode initially stronger personal norms.

An important issue for future criminological research lies in the examination of the same type of crime by means of different methods. If, like in the present study, similar results are found when using dissimilar methods, this greatly increases confidence in the findings. A particular interesting avenue for further bribery research lies in the quantitative examination of relationship factors, as these seem to be relevant in explaining bribery but currently are understudied. Since case-studies cannot establish whether the factors that seem present in the investigated cases are actually related to people's engagement in bribery, questionnaires could be administered to assess to what extent different relationship factors correlate with corruption. For instance, by means of a questionnaires study, researchers could examine whether employees are more prone to corruption if they engage in frequent interactions with business contacts outside work and working hours; or whether personal and amicable interactions with business relations, or a (suddenly) increased intensity of these interactions, increase employees' proneness to engage in bribery. By administering the same questionnaire to the same respondents at different moments in time, thus following a longitudinal research design, insight can be gained into how these factors and processes evolve across time. By doing so, it can for instance be established if a personal and intensive relationship precedes people's engagement in a corrupt collaboration, or results from it.

The present study included different types of factors and suggests corruption is the result of an interplay between these factors. A fascinating topic for future research is a further examination of the interplay between factors that gives rise to a person's engagement in corruption. For instance, future studies could investigate how organizational and individual factors, such as absent ethical leadership and weak personal norms, are related not only to corruption, but also to each other, and how they together shape corruption. In particular, future studies could examine how and under which conditions individual, organizational and relationship reinforce each other and form a toxic mix, and assess whether these three type of factors are all necessary for a toxic mix to arise, or whether one or a few factors play a critical role, and can affect other factors for the worse, in turn leading to a self-reinforcing process. A better understanding of the interplay and dynamics between factors will enable more effective and efficient anti-corruption interventions to be developed that withhold public officials from putting government decisions 'up for sale'.

Since this study focused on a specific form of crime, bribery, in a specific context (i.e., the bribery of public officials by company representatives), further research is required in order to study whether similar factors play a role in bribery in other contexts, such as the bribery of public officials by criminal organizations instead of 
legitimate organizations, or bribery between private companies (i.e., private-to-private corruption, see [78]). Moreover, future studies could examine whether similar individual factors, organizational factors and relationship factors underlie people's engagement in forms of corruption requiring the involvement of multiple offenders, such as business cartels (see for instance [79]). In addition, since this study was conducted in the Netherlands, future studies are required to examine the extent to which the findings can be generalized to other cultures and societies, both Western and Non-Western. In doing so, researchers could, additionally, examine to what extent and how macro factors, such as political institutions [80], and the culture in a country [81, 82], affect the individual, organizational and relationship factors we studied, and how the four types of factors affect corruption together.

Our study has important practical implications as its findings indicate that bribery results from a combination of individual, organizational and relationship factors that co-occur and reinforce each other. The results point to a strong contamination of the perpetrators' environment, and particularly the officials' colleagues. Therefore, a corrupt official under scrutiny should not too readily be seen as an isolated 'bad apple'. The offender may have been spreading rot in the 'barrel' (i.e., the organization), or may have been infected by other rotten apples that have not yet been identified as corrupt, or by a barrel initiating the rotting process. Therefore, besides removing the corrupt employee, it seems wise, both for the organization and the investigation service, to also look for other possible affected apples, or even for a 'corrupting barrel'. If the barrel seems 'bad', targeted measures are needed to prevent further infections. With regard to preventing corruption, the possible interdependence between the factors also offers opportunities for change: changing one critical factor, such as appointing supervisors who timely and adequately respond to warning signs and who set the right example, may prevent, or defuse, the toxic mix that leads to corruption.

In summary, the engagement of public officials in bribery seems to be rooted in a combination of individual, organizational and relationship variables that reinforce each other, creating a toxic mix. This implies that the battle against corruption can be fought on multiple fronts, whereby changing one critical factor may cause the mix to lose its toxicity.

Acknowledgements We thank the National Police Internal Investigations Department and the Fiscal Information and Investigation Service. Without their cooperation, we could have not conducted this study.

Funding This work was supported by the National Police Internal Investigations Department (in Dutch: Rijksrecherche). ${ }^{24}$

\section{Compliance with ethical standards}

Conflict of interest The authors declare that they have no conflict of interest.

\footnotetext{
${ }^{24}$ This study was part of a $\mathrm{PhD}$ project sponsored by PwC the Netherlands. The present study was, however, carried out as a separate research assignment, sponsored by the National Police Internal Investigations Department.
} 


\section{Appendix 1: Scoring form}

Individual-level factors

Perceived benefits of bribery (multiple options possible)

1. Financial/material gain

2. Status

3. Achieve targets/secure one's job

4. Respect/appreciation (from business partners/friends/family)

5. Excitement

6. Do pleasurable things

7. Love

8. Way to handle frustration (e.g. about work/colleagues/supervisors)

9. etc.

Perceived costs of bribery

1. Perceived risk of detection by: direct colleague/supervisor/colleague of the briber/competitor of the briber/enforcement agency

2. Perceived severity of detection and punishment direct: loss of job/fine/arrest/prison indirect: devalued opinion of colleagues, friends and family

Perceived opportunities for bribery

1. Perceived ease to violate bribery regulations

2. Perceived difficulty to comply to bribery regulations

Personal norms on bribery

Absence of ...

1. Feelings of moral obligation refrain from bribery

2. Awareness of bribery's negative consequences

3. Feelings of personal responsibility for these negative consequences

\section{Social norms on bribery}

Perception of ...

1. Whether others approve of bribery (injunctive norms)

2. Whether others engage in bribery (descriptive norms)

Organizational-level factors

\section{Structural organizational factors}

Prevention \& detection of bribery

Did the corrupt official's organization take measures to prevent/ detect bribery?

1. Segregation of duties and job rotation for sensitive positions

2. Compliance-/ integrity department

3. Systematic internal controls, risk analyses and audits

4. Reporting system (e.g. whistleblower hotline)

5. Transparent rules and codes of conduct regarding bribery

(i.e., rules on sideline activities and the acceptance of gifts)

6. Training of staff and managers on ethics/integrity

7. Confidential counselor

How can the reward system within the organization be qualified?

Important role of ...

1. Targets

2. Bonuses

3. Other forms of special rewards (e.g. bonuses for exceptional performance)

4. Did the corrupt official (shortly before the bribery was discovered) receive a special reward?

5. Did the corrupt official (before the bribery was discovered) receive a warning or 'punishment' (e.g. transfer/demotion/no promotion etc.)? 


\section{Cultural organizational factors \& leadership}

Ethical virtues of the organizational culture ${ }^{25}$

1. Clarity (concrete, comprehensive and understandable ethical guidelines for management and employees)

2. Congruency (behavior of management and supervisors is in accordance with: the ethical expectations/tone at the top/example set by managers and supervisors)

3. Feasibility (organization provides enough: time/budgets/ equipment/ information and authority to management and employees to act ethical responsibly)

4. Supportability (the organization stimulates identification with and commitment to ethical expectations among management and employees)

5. Transparency (consequences of ethical and unethical behavior are visible for both managers and employees who can act upon it)

6. Discussability (ethical issues, such as ethical dilemmas and alleged unethical behavior, can be raised and discussed among managers and employees)

7. Sanctionability (managers and employees believe that unethical behavior will be punished and ethical behavior will be rewarded)

Relationship-level factors

\section{Relationship between the public official and company representative(s)}

How did the corrupt parties know each other (business or private sphere)?

Was the nature of the relationship predominantly affective or instrumental?

How long had they known each other (i.e. before engaging in bribery)?

When did their relationship turn into a corrupt collaboration?

\section{The corrupt collaboration}

Who initiated the bribery?

1. The briber

2. The bribee

3. Both (i.e. in case of multiple corrupt exchanges)

How did the corrupt interactions between the corrupt parties take place?

1. Via direct/physical contact

2. By phone

3. By email

Where did the corrupt interactions take place?

1. At work

2. At home

3. Somewhere else

Which decision did the briber wish to influence/what preferential treatment did the briber aim for?

What did the return favor to the public officials consist of?

Who came up with the bribery construction (the briber/the bribee/others)?

How implicit or explicit were the conversations/agreements about the corrupt exchange?

In which order did the exchange take place

(first the preferential treatment and then the return favor/vice versa/unclear)?

How often did a corrupt exchange take place (e.g. only once, often etc.)

Are there indications for a 'slippery slope' (i.e. did the bribery gradually increase in severity over time)?

Are there indications the briber/bribee at some point wanted to end the corrupt collaboration? If so, why? Were these attempts successful? If not, why?

Other questions

\section{Detection}

By whom and how did the bribery come to light

(e.g. colleague/supervisor/internal controls/external controls/by coincidence)?

\footnotetext{
${ }^{25}$ Based on 'The corporate ethical virtues model' [57]. See also: http://www.ethicsmanagement.info/content. php?pagina $=2 \&$ type $=0$
} 
Before the bribery was criminally investigated, had there been people who knew about the bribery, who spoke about it or reported it?

\section{Outcome of the criminal investigation}

What was the outcome of the criminal investigation

(e.g. warning/transfer/ departure scheme/dismissal/ prosecution)?

\section{Other rule-violating behavior}

Did the corrupt official engage in unethical and/or illegal behavior besides bribery?

1. Other criminal offences

2. Other violations

3. Other unethical behavior

Open Access This article is licensed under a Creative Commons Attribution 4.0 International License, which permits use, sharing, adaptation, distribution and reproduction in any medium or format, as long as you give appropriate credit to the original author(s) and the source, provide a link to the Creative Commons licence, and indicate if changes were made. The images or other third party material in this article are included in the article's Creative Commons licence, unless indicated otherwise in a credit line to the material. If material is not included in the article's Creative Commons licence and your intended use is not permitted by statutory regulation or exceeds the permitted use, you will need to obtain permission directly from the copyright holder. To view a copy of this licence, visit http://creativecommons.org/licenses/by/4.0/.

\section{References}

1. Chan, T. (2000). Corruption prevention - The Hong Kong experience. UNAFEI Resource Material Series, 56, 365-377.

2. Rose-Ackerman, S. (2007). International handbook on the economics of corruption. Cheltenham UK: Edward Elgar Publishing.

3. de Graaf, G., von Maravić, P., \& Wagenaar, P. (2010). The good cause: Theoretical perspectives on corruption. Opladen \& Farmington Hills, MI: Barbara Budrich Publisher.

4. Köbis, N. C., Van Prooijen, J.-W., Righetti, F., \& Van Lange, P. A. M. (2015). "Who Doesn't?”-The impact of descriptive norms on corruption. PLoS One, 10(6), e0131830.

5. Dong, B., Dulleck, U., \& Torgler, B. (2012). Conditional corruption. Journal of Economic Psychology, 33(3), 609-627.

6. Svensson, J. (2003). Who must pay bribes and how much? Evidence from a cross section of firms. Quarterly Journal of Economics, 118(1), 207-230.

7. Aguilera, R. V., \& Vadera, A. K. (2008). The dark side of authority: antecedents, mechanisms, and outcomes of organizational corruption. Journal of Business Ethics, 77(4), 431-449.

8. Tanzi, V. (1998). Corruption around the world - Causes, consequences, scope, and cures. International Monetary Fund Staff Papers, 45(4), 559-594.

9. Jordan, J. (2011). The adequate procedures defense under the UK bribery act: a British idea for the foreign corrupt practices act. Stanford Journal of Law, Business \& Finance, 17(1), 25-66.

10. Sampford, C. J., Shacklock, A. H., Connors, C., \& Galtung, F. (2006). Measuring corruption. Hampshire: Ashgate Publishing Limited.

11. Benson, G. C. (1989). Codes of ethics. Journal of Business Ethics, 8(5), 305-319.

12. Lord, N. J. (2014). Responding to transnational corporate bribery using international frameworks for enforcement: anti-bribery and corruption in the UK and Germany. Criminology \& Criminal Justice, 14(1), 100-120.

13. Rose-Ackerman, S. (1997). The political economy of corruption. In K. A. Elliott (Ed.), Corruption and the global economy (pp. 31-60). Washington, DC: Institute for International Economics.

14. Gorsira, M., Denkers, A. J. M., \& Huisman, W. (2016). Both sides of the coin: motives for corruption among public officials and business employees. Journal of Business Ethics, 1-16. 
15. Becker, G. S. (1968). Crime and punishment: an economic approach. The Journal of Political Economy, 169, 176-177.

16. Simpson, S. S., Piquero, N. L., \& Paternoster, R. (2002). Rationality and corporate offending decisions. In A. Piquero \& S. G. Tibbetts (Eds.), Rational choice and criminal behavior: Recent research and future challenges (pp. 25-32). New York: Routledge.

17. Paternoster, R., \& Simpson, S. (1993). A rational choice theory of corporate crime. In R. V. Clarke \& M. Felson (Eds.), Advances in criminological theory, Vol. 5. Routine activity and rational choice (pp. 3758). Transaction Publishers.

18. Andvig, J. C., Fjeldstad, O. H., Amundsen, I., Sissener, T., \& Søreide, T. (2001). Corruption. A review of contemporary research. Bergen: Chr. Michelsen Institute.

19. Dimant, E. (2013). The nature of corruption: An interdisciplinary perspective. German Law Journal, 17(1), 53-72.

20. Prabowo, H. Y. (2014). To be corrupt or not to be corrupt: understanding the behavioral side of corruption in Indonesia. Journal of Money Laundering Control, 17(3), 306-326.

21. Agnew, R. (2014). Social concern and crime: moving beyond the assumption of simple self-interest. Criminology, 52(1), 1-32.

22. Cohen, L. E., \& Felson, M. (1979). Social change and crime rate trends: a routine activity approach. American Sociological Review, 588-608.

23. Gottfredson, M. R., \& Hirschi, T. (1990). A general theory of crime. Stanford: Stanford University Press.

24. Benson, M. L., Madensen, T., \& Eck, J. (2009). White-collar crime from an opportunity perspective. In S. Simpson \& D. Weisburd (Eds.), The criminology of white-collar crime (pp. 175-193). New York: Springer.

25. Graycar, A., \& Sidebottom, A. (2012). Corruption and control: a corruption reduction approach. Journal of Financial Crime, 19(4), 384-399.

26. Pinto, J., Leana, C. R., \& Pil, F. K. (2008). Corrupt organizations or organizations of corrupt individuals? Two types of organization-level corruption. Academy of Management Review, 33(3), 685-709.

27. Ajzen, I. (1991). The theory of planned behavior. Organizational Behavior and Human Decision Processes, 50(2), 179-211.

28. Bandura, A. (1977). Self-efficacy: toward a unifying theory of behavioral change. Psychological Review, 84(2), 191-215.

29. Fishbein, M., \& Cappella, J. N. (2006). The role of theory in developing effective health communications. Journal of Communication, 56, S1-S17.

30. Ajzen, I. (1985). From intentions to actions: A theory of planned behavior. In J. Kuhl \& J. Beckmann (Eds.), Action-control: From cognition to behavior (pp. 11-39). Heidelberg: Springer.

31. Schwartz, S. H. (1977). Normative influences on altruism. Advances in Experimental Social Psychology, 10, 221-279.

32. Cialdini, R. B., Reno, R. R., \& Kallgren, C. A. (1990). A focus theory of normative conduct: recycling the concept of norms to reduce littering in public places. Journal of Personality and Social Psychology, 58(6), 1015-1026.

33. Schwartz, S. H., \& Howard, J. A. (1981). A normative decision-making model of altruism. In J. P. Rushton \& R. M. Sorrentino (Eds.), Altruism and helping behavior (pp. 189-211). Hillsdale, NJ: Erlbaum.

34. Powpaka, S. (2002). Factors affecting managers' decision to bribe: an empirical investigation. Journal of Business Ethics, 40(3), 227-246.

35. Rabl, T. (2011). The impact of situational influences on corruption in organizations. Journal of Business Ethics, $100(1), 85-101$.

36. Tavits, M. (2010). Why do people engage in corruption? The case of Estonia. Social Forces, 88(3), 1257-1279.

37. Shover, N., \& Bryant, K. M. (1993). Theoretical explanations of corporate crime. In M. B. Blankenship (Ed.), Understanding corporate criminality (pp. 141-176). New York: Garland Publishing.

38. Rabl, T., \& Kühlmann, T. M. (2008). Understanding corruption in organizations - development and empirical assessment of an action model. Journal of Business Ethics, 82(2), 477-495.

39. Kish-Gephart, J. J., Harrison, D. A., \& Treviño, L. K. (2010). Bad apples, bad cases, and bad barrels: meta-analytic evidence about sources of unethical decisions at work. Journal of Applied Psychology, 95(1), 1-31.

40. Huisman, W. (2016). Criminogenic organizational properties and dynamics. In S. R. Van Slyke, M. L. Benson, \& F. T. Cullen (Eds.), The Oxford handbook of white-collar crime (pp. 435-462). New York: Oxford University Press. 
41. Ashforth, B. E., Gioia, D. A., Robinson, S. L., \& Treviño, L. K. (2008). Re-viewing organizational corruption. Academy of Management Review, 33(3), 670-684.

42. Coleman, J. W. (1987). Toward an integrated theory of white-collar crime. American Journal of Sociology, 93, 406-439.

43. Levi, M. (2008). Organized fraud and organizing frauds: unpacking research on networks and organization. Criminology \& Criminal Justice, 8(4), 389-419.

44. Free, C., \& Murphy, P. R. (2015). The ties that bind: the decision to co-offend in fraud. Contemporary Accounting Research, 32(1), 18-54.

45. Anand, V., Ashforth, B. E., \& Joshi, M. (2004). Business as usual: the acceptance and perpetuation of corruption in organizations. The Academy of Management Executive, 18(2), 39-53.

46. Treviño, L. K., Weaver, G. R., Gibson, D. G., \& Toffler, B. L. (1999). Managing ethics and legal compliance: what works and what hurts. California Management Review, 41(2), 131-151.

47. Adams, M. B. (1994). Agency theory and the internal audit. Managerial Auditing Journal, 9(8), 8-12.

48. Wells, J. T., \& Gill, J. D. (2007). Assessing fraud risk. Journal of Accountancy, 204(4), 63-65.

49. Armstrong, E. (2005). Integrity, transparency and accountability in public administration: Recent trends, regional and international developments and emerging issues. United Nations.

50. Schwartz, M. S. (2016). Ethical decision-making theory: an integrated approach. Journal of Business Ethics, 139(4), 755-776.

51. Goel, R. K., Budak, J., \& Rajh, E. (2015). Private sector bribery and effectiveness of anti-corruption policies. Applied Economics Letters, 22(10), 759-766.

52. Armantier, O., \& Boly, A. (2011). A controlled field experiment on corruption. European Economic Review, 55(8), 1072-1082.

53. Schulze, G. G., \& Frank, B. (2003). Deterrence versus intrinsic motivation: experimental evidence on the determinants of corruptibility. Economics of Governance, 4(2), 143-160.

54. de Graaf, G., \& Huberts, L. W. J. C. (2008). Portraying the nature of corruption using an explorative case study design. Public Administration Review, 68(4), 640-653.

55. Abbink, K. (2004). Staff rotation as an anti-corruption policy: an experimental study. European Journal of Political Economy, 20(4), 887-906.

56. Gorsira, M., Steg, L., Denkers, A. J. M., \& Huisman, W. (2018). Corruption in organizations: ethical climate and individual motives. Administrative Sciences, 8(4), 1-19.

57. Kaptein, M. (2008). Developing and testing a measure for the ethical culture of organizations: the corporate ethical virtues model. Journal of Organizational Behavior, 29(7), 923-947.

58. Peterson, D. K. (2002). Deviant workplace behavior and the organization's ethical climate. Journal of Business and Psychology, 17(1), 47-61.

59. Treviño, L. K., Butterfield, K. D., \& McCabe, D. L. (1998). The ethical context in organizations: influences on employee attitudes and behaviors. Business Ethics Quarterly, 8(03), 447-476.

60. Victor, B., \& Cullen, J. B. (1988). The organizational bases of ethical work climates. Administrative Science Quarterly, 33(1), 101-125.

61. Dickson, M. W., Smith, D. B., Grojean, M. W., \& Ehrhart, M. (2001). An organizational climate regarding ethics: the outcome of leader values and the practices that reflect them. The Leadership Quarterly, 12(2), 197-217.

62. Huberts, L. W. J. C., Kaptein, M., \& Lasthuizen, K. (2007). A study of the impact of three leadership styles on integrity violations committed by police officers. Policing: An International Journal of Police Strategies \& Management, 30(4), 587-607.

63. Köbis, N. C., van Prooijen, J.-W., Righetti, F., \& Van Lange, P. A. M. (2017). The road to bribery and corruption: slippery slope or steep. A Danish corruption tale. Journal of Scandinavian Studies in Criminology and Crime Prevention, 13(2), 133-141.

64. Johnston, W. J., Leach, M. P., \& Liu, A. H. (1999). Theory testing using case studies in business-tobusiness research. Industrial Marketing Management, 28(3), 201-213.

65. Luck, L., Jackson, D., \& Usher, K. (2006). Case study: a bridge across the paradigms. Nursing Inquiry, 13(2), 103-109.

66. Maruna, S. (2010). Mixed method research in criminology: Why not go both ways? In A. Piquero \& D. Weisburd (Eds.), Handbook of quantitative criminology. New York: Springer.

67. de Graaf, G., Huberts, L. W. J. C., \& Nelen, J. M. (2008). Is the glass half full or half empty? Perceptions of the scale and nature of corruption in the Netherlands. Perspectives on European Politics and Society, 9(1), 84-94.

68. Benson, M. L., \& Simpson, S. S. (2018). White-collar crime: An opportunity perspective (3rd ed.). Taylor \& Francis. 
69. Sykes, G. M., \& Matza, D. (1957). Techniques of neutralization: a theory of delinquency. American Sociological Review, 22(6), 664-670.

70. Stadler, W. A., \& Benson, M. L. (2012). Revisiting the guilty mind: the neutralization of white-collar crime. Criminal Justice Review, 37(4), 494-511.

71. Whyte, D. (2016). It's common sense, stupid! Corporate crime and techniques of neutralization in the automobile industry. Crime, Law and Social Change, 66(2), 165-181.

72. Zyglidopoulos, S. C., Fleming, P. J., \& Rothenberg, S. (2009). Rationalization, overcompensation and the escalation of corruption in organizations. Journal of Business Ethics, 84, 65-73.

73. Aquino, K., \& Becker, T. E. (2005). Lying in negotiations: how individual and situational factors influence the use of neutralization strategies. Journal of Organizational Behavior, 26(6), 661-679.

74. Festinger, L. (1957). A theory of cognitive dissonance. Evanston: Row, Peterson.

75. Schwartz, S. H., \& Howard, J. A. (1980). Explanations of the moderating effect of responsibility denial on the personal norm-behavior relationship. Social Psychology Quarterly, 43(4), 441-446.

76. Fijnaut, C. J. C. F. (1993). Politiële corruptie in Nederland: Een Impressie van Veertien Gevallen [PoliceCorruption in the Netherlands: An impression of fourteen cases]. Arnhem: Gouda Quint.

77. Mazar, N., Amir, O., \& Ariely, D. (2008). The dishonesty of honest people: a theory of self-concept. maintenance. Journal of Marketing Research, 45(6), 633-644.

78. Argandoña, A. (2003). Private-to-private corruption. Journal of Business Ethics, 47(3), 253-267.

79. Jaspers, J. D. (2017). Managing cartels: how cartel participants create stability in the absence of law. European Journal on Criminal Policy and Research 23, 319-335.

80. Lederman, D., Loayza, N. V., \& Soares, R. R. (2005). Accountability and corruption: political institutions matter. Economics \& Politics, 17(1), 1-35.

81. Davis, J. H., \& Ruhe, J. A. (2003). Perceptions of country corruption: antecedents and outcomes. Journal of Business Ethics, 43(4), 275-288.

82. Husted, B. W. (1999). Wealth, culture, and corruption. Journal of International Business Studies, 30(2), 339-359.

Publisher's note Springer Nature remains neutral with regard to jurisdictional claims in published maps and institutional affiliations. 